\title{
UNA APROXIMACIÓN AL LIBRO PERCEPCIÓN Y CREATIVIDAD DE HUBERTO BOGAERT GARCÍA
}

\section{An Approximation to the book Perception and Creativity of Huberto Bogaert García}

\section{Rocío Hernández Mella \\ Profesora-investigadora del Área de Ciencias Sociales y Humanidades del Instituto Tecnológico de Santo Domingo, INTEC. Correo-e: rocio.hernandez@intec.edu.do ORCID: 0000-0002-1331-5453}

Recibido: 2/4/2019 • Aprobado: 30/4/2019

Cómo citar: Hernández Mella, R. (2019). Una aproximación al texto percepción y creatividad de Huberto Bogaert García. Ciencia y Sociedad, 44(2), 89-93. Doi: https://doi.org/10.22206/cys.2019.v44i2.pp89-93

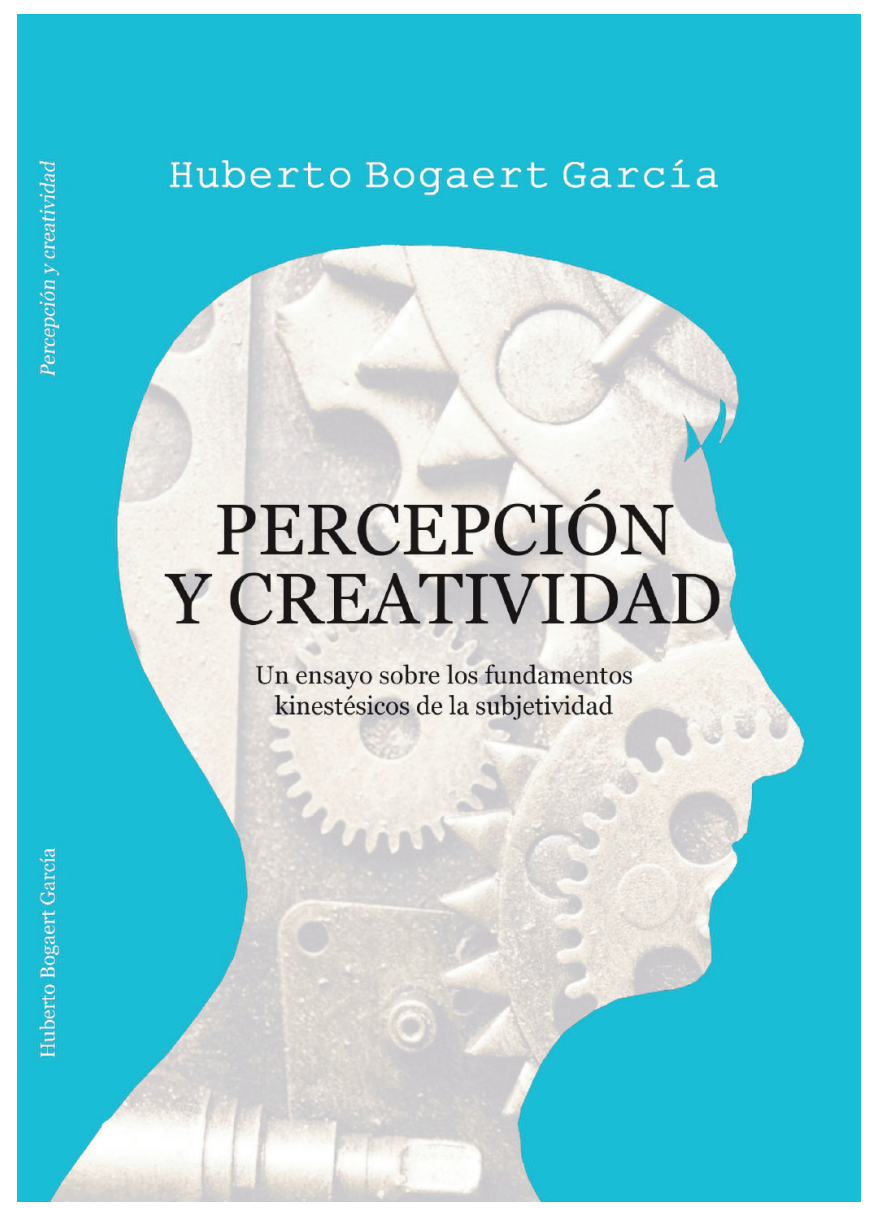

El libro Percepción y creatividad. Un ensayo sobre los fundamentos kinestésicos de la subjetividad (2018) del Dr. Huberto Bogaert, publicado por el Instituto Tecnológico de Santo Domingo, es un texto que exhibe argumentos y demostraciones a favor del movimiento en la construcción de la conciencia, a la vez que favorece los procesos de percepción y creatividad como relevantes en la emergencia del sí mismo. El autor manifiesta un interés por preservar la unidad del sistema cerebro-mente, más allá de que ambos componentes se despliegan en dos universos distintos, el primero físico y el segundo simbólico o imaginario. Es decir, y en sus propias palabras, "se requiere de un modelo integrador que acoja lo experimental y lo hermenéutico, la explicación científica y la interpretación..." (p. 12).

En esta reseña se presentan las perspectivas teóricas utilizadas por Bogaert, las definiciones de los dos conceptos más importantes del texto y se reelabora la reflexión seguida por el autor que apoya sus explicaciones acerca de los fundamentos kinestésicos de la subjetividad. Se finaliza con el aporte relativo al poder predictivo del Test de Rorschach sobre la capacidad creativa. 


\section{Perspectivas teóricas}

Las perspectivas teóricas en las cuales Bogaert se fundamenta provienen de las neurociencias, el psicoanálisis, sobre todo lacaniano, y la fenomenología. De las primeras, recalca que el modelo neurobiológico muestra cambios derivados de su focalización mayor en el funcionamiento del cerebro-mente. El cerebro humano se concibe como un organismo "cuyo desarrollo incorpora las improntas epigenéticas que se establecen por selección y variación" (p. 14), con lo cual es posible afirmar que la persona se construye a sí misma, no solo a nivel psicológico, sino biológicamente también.

En cuanto al psicoanálisis, el autor enfatiza que se trata de la aproximación que "revela la dimensión transubjetiva de la génesis del sí mismo” (p. 17), por lo que la palabra que intercomunica resulta esencial. Y, por último, con la fenomenología se descubre que el ser humano establece un diálogo con sus congéneres al mismo tiempo que con la naturaleza, donde es el cuerpo lo que posibilita aprehender el mundo.

\section{Percepción y creatividad}

La percepción se define como un aspecto de la realidad sensomotora y se construye a partir de la acción. Lo inicial a destacar, según Bogaert, es el interés que muestra el cerebro humano por evidenciar lo que es constante, en lo que se refiere a las propiedades características de los objetos, contrario al hecho de que la información aportada por el mundo exterior no es fija, sino variable. Es decir, que el cerebro genera sus propias percepciones, con lo cual, a partir de una serie de explicaciones y con la evidencia aportada por neurólogos, el autor concluye que "para el cerebro la única realidad es la que él mismo elabora” (p. 75). Además, la percepción no resulta ser un acto pasivo, una mera contemplación, sino que se reconoce la importancia de los movimientos del cuerpo en el individuo que percibe, nos presenta el autor, siguiendo a Husserl (1982), haciendo evidente que la conciencia perceptiva es inseparable del cuerpo en movimiento.

Por otro lado, afirma que "la percepción siempre está mediada por lo imaginario y lo simbólico" (p. 84). Esto se sustenta en que el sistema nervioso, durante la acción imaginada, se comporta de manera afín a la preparación para realizar la acción real. Quiere decir que "ver actuar" se corresponde con el actuar, según un mismo patrón neuronal, plantea Bogaert.

La conciencia de lo percibido sucede gracias a la represión de la sensación; esto es, desde el ser consciente, aquello que siente el cuerpo se consigue colocar en el inconsciente. De hecho, la experiencia de la conciencia se vive como que ocurre fuera de la realidad somática. Tal separación entre el sentimiento y la conciencia se asume como necesaria al lograr "la inconsciencia de su cuerpo, en tanto objeto del deseo materno” (p.148), alejándose así de la angustia que produce la sensación.

La creatividad se encuentra vinculada al insight y la intuición. El primero se concibe como una visión interior súbita o manera poco usual de comprender una situación o problema, puesto que no se trata de una deducción o de un proceso inductivo, sino de una experiencia integral expresada de modo unitario. Se asocia a la contemplación y Bogaert explica que en su producción está implicada la corteza cerebral del hemisferio derecho. La intuición, por su lado, es entendida como la aprehensión directa de un conocimiento que ocurre en ausencia de una reflexión propiamente dicha. A destacar se encuentra la afirmación del autor acerca de las personas intuitivas como capaces de captar sus sensaciones kinestésicas y las de los demás, a través de lo que Bogaert enuncia como “comunicación transubjetiva” (p. 43). La explicación ofrecida consiste en que una mente inconsciente se comunica con otra mente inconsciente, u otra manera de conceptuarlo sería que el inconsciente se crea en el intercambio entre los dos sujetos. 
El acto intuitivo permite una atención interior del sujeto con su imagen corporal y sus sensaciones, lo que, a su vez, hace posible que las sensaciones y hasta los pensamientos de las demás personas repercutan en sí mismo. El requisito para que este acto ocurra es una actitud abierta y el estar receptivo a lo que acontece.

Para algunos autores citados por Bogaert, la creatividad proviene de la dependencia de un estado de permanente insatisfacción, lo que estimula el área orbitofrontal y que se corresponde con el reservorio que Freud (1973) concibió como energía psíquica, estipula nuestro autor. Dicha energía, cuando logra sublimarse, intenta conseguir un goce creativo.

La persona creadora, según el autor, es poco convencional, busca transformar aquello que está establecido, sea un conocimiento científico o un estilo artístico, es capaz de jugar con la deconstrucción y todo por alcanzar la plenitud, si bien conducida por el reclamo narcisista a generar cambios de perspectiva.

\section{La subjetividad y sus fundamentos kinestésicos}

Por subjetividad Bogaert entiende el proceso activo de la conciencia. Al tratar los aspectos neurobiológicos, el autor introduce el concepto de cualia, apreciado como una experiencia subjetiva referida a los cinco sentidos, la propiocepción, la kinestesia, así como el placer y el dolor. Ahora bien, la cualia es un estado psicológico, que depende de un estado físico, pero que este último no lo causa.

La conciencia o subjetividad no puede reducirse al órgano cerebral, si bien, tal y como expone Bogaert, su naturaleza tálamocortical, por la vía de una disposición funcional preexistente, posibilita que la entrada sensorial del mundo externo adquiera significado para la persona. El cerebro hasta puede generar imágenes en ausencia de señales provenientes de los sentidos, tal y como se observa en los sueños o las fantasías. Incluso se reconoce la plasticidad cerebral, así como el rol del desarrollo epigenético en el ser humano.
Sin embargo, el cerebro no puede ser examinado por los sentidos o, como escribe el autor, "no lo sentimos, no se mueve y no experimenta dolor" (p. 101) y el sujeto interpreta el mundo de acuerdo con sus a priori neurológicos.

En cambio, según Bogaert, la experiencia consciente se da de manera indivisible, es privada y resulta altamente diferenciada, por lo que la subjetividad es irreductible. De ahí que los registros neurofisiológicos no pueden aprehender la riqueza de una vivencia que se produce de forma consciente.

Iniciando por el movimiento, de todas las capacidades de la conciencia y figuras de la psique explicadas, Bogaert expresa que no se origina en el cuerpo físico exclusivamente, sino que existe el "movimiento psíquico" (p. 155) y enfatiza que es el ritmo del cuerpo o del movimiento mental lo que hace surgir la excitación y el deseo.

La libido, que se encuentra en la base del psiquismo, el autor la concibe como un patrón neural que emerge como representación psíquica. El ello se asume como un gran reservorio de la libido y anima el cuerpo, puesto que este último no se resume a lo físico.

El movimiento resulta ser la fuente kinestésica de la abstracción y del juicio y ambas capacidades se hacen posible grac ias al lenguaje y enfatiza que aquél constituye el fundamento de la subjetividad.

El lenguaje introduce en el ser humano "un modo peculiar de percibir y de relacionarse con el ambiente" (p. 119) y Bogaert lo incluye dentro de la categoría de "patrón de acción fijo" o PAF premotor, que está relacionado con la actividad de los ganglios basales y constituye una prioridad que resulta intrínseca del cerebro humano. Ahora bien, para que el lenguaje pueda surgir necesita un sistema nervioso con capacidad para crear imágenes premotoras, ya que estas últimas posibilitan abstraer las propiedades de los objetos. Tal afirmación conduce a establecer que el pensamiento evolucionó antes que el 
lenguaje, adicionalmente al hecho de estimar que los eventos premotores de ambos procesos son los mismos que preceden a cualquier movimiento que se ejecute con una intención determinada. De ahí que el autor sostenga que la subjetividad posee un fundamento kinestésico.

El pensamiento resulta de la interiorización y de la verbalización del movimiento, ya que la actividad cognoscitiva del ser humano se apoya en la acción sensomotora. Desde la concepción neuropsicoanalítica, la aparición del lenguaje transforma el objeto al articular el espacio, haciendo surgir una perspectiva que se aleja de lo real; las palabras hacen referencia a otras palabras, en vez de a las cosas, por lo que Bogaert manifiesta que "el lenguaje impone al hombre un exilio de lo real" (p. 149).

Otro patrón de acción fijo o PAF premotor corresponde a la pulsión y, al igual que los afectos básicos, son heredados, pero, a la vez, modificables. Es por esa plasticidad que la pulsión deviene en un concepto límite entre lo orgánico y lo psíquico y representa, para el autor, la unidad biopsíquica del ser humano. Las pulsiones se manifiestan mediante acciones, como el acto fallido, el acting out, el pasaje al acto; así como en el lenguaje del tipo lapsus u olvido y, por último, en emociones y síntomas.

Por medio de la represión de las pulsiones que ocurre a través de la palabra se da lo que el autor afirma como "la impronta definitiva del cuerpo psíquico sobre lo orgánico" (p. 135). Las pulsiones, que se originan en el ello, pueden tomarse como indicativas de la primera etapa del proceso de interiorización del movimiento, en el hemisferio derecho. Y para Braunstein (1987, citado por Bogaert, 2018) se encuentran vinculadas al deseo del otro. Para Freud, según nuestro autor, aquello que en primera instancia resulta ser una necesidad en el bebé, se convierte en pulsión a partir de un recuerdo asociado con su satisfacción.

El sí mismo surge en el momento en que se internaliza la experiencia con el otro y se incorporan las representaciones interactivas. El núcleo del sí mismo es inconsciente y sus funciones se asocian con las áreas orbitofrontales, que desde el punto de vista evolutivo Bogaert supone que tiene como soporte el aparato motor.

Panksepp (1988, citado por Bogaert, 2018) sostiene que el sí mismo surge a partir de la regulación de la actividad motora y la conciencia que promueve es primordialmente afectiva, aunque es capaz de generar cogniciones y aprendizajes muy simples, que se mantienen en el inconsciente, a través de sistemas subcorticales. El sí mismo hace surgir la subjetividad y ese momento coincide con "la represión originaria y con la constitución del ideal del yo" (p. 115), además de la acción voluntaria estar en el origen de dicha subjetividad. El yo ideal da cuenta de aquellos ideales que son promovidos por la cultura.

\section{El test de Rorschach como predictor de la creatividad}

La relevancia de la respuesta kinestésica para Bogaert incluye una valoración de aquellos sujetos que la presentan, por ser personas que poseen una inteligencia más diferenciada y una productividad muy personal. En adición, el autor aporta que dicha respuesta kinestésica es "una creación que tiene su origen en un deseo inconsciente que, al no poder traducirse en actos motores, actualiza engramas kinestésicos" (p. 57). La respuesta kinestésica (K) es una creación del sujeto, en el sentido que no está determinada por un estímulo sensorial real; es decir, que la $\mathrm{K}$ es una interpretación personal de un estímulo y es esencialmente proyectiva, a juicio del autor.

Bogaert propone el test de Rorschach como predictor de la creatividad debido a que la ambigüedad que presentan las láminas es lo que da pie a las respuestas originales en determinadas personas:

En el test de Rorschach, la respuestakinestésica se proyecta porque el vacío de la lámina 
genera angustia y provoca una vacilación perceptiva, hasta que surge la unidad de la forma humana en movimiento, que en cierto modo participa en el intercambio como un interlocutor silencioso (pp. 144-145)

En el ser humano existe el movimiento oscilatorio del fort-da que se encuentra en la base de la subjetividad, el cual, y de acuerdo al autor, es básicamente narcisístico, ya que se relaciona con la angustia de separación de la madre. Esa angustia reaparece ante el vacío de las láminas del test de Rorschach, que la respuesta kinestésica permite superar creativamente. La importancia del advenimiento del narcisismo es que aparece el registro de lo imaginario, asimismo, se establece la unidad de la imagen del cuerpo.

La hipótesis del autor, demostrada en investigaciones que ha llevado a cabo, trata acerca de cómo la respuesta de movimiento dada por el individuo es indicativa de su capacidad para situarse en un espacio de transición entre la realidad y el "investimiento subjetivo" (p. 172) de ella. Del mismo modo, la respuesta kinestésica hace evidente que existe actividad mental que reorganiza los datos perceptivos de un modo creativo. En definitiva, las respuestas $\mathrm{K}$ son un indicador de la originalidad de la persona; da cuenta de la capacidad creativa del sujeto, y con su propuesta, Bogaert da pie para la creación del modelo integrador del sistema cerebro-mente:

Por nuestra parte, hemos recurrido a la respuesta kinestésica del test de Rorschach como un indicador psicológico objetivo capaz de establecer un entredós que permite articular el enfoque experimental en tercera persona y la experiencia personal, en primera persona (p. 188).

\section{Datos de filiación}

Rocío Hernández Mella. Profesora-investigadora del Área de Ciencias Sociales y Humanidades del Instituto Tecnológico de Santo Domingo, INTEC. Doctora en Psicología Social; maestría en Planificación y Administración de la Educación; especialización en Psicología Educativa y licenciatura en Psicología. Consultora en Psicología y Educación para OEI-República Dominicana y el MINERD; coordinadora Educativa del Centro Jung Santo Domingo y vicepresidenta de la Fundación Tonucci: Educando para la Diversidad. 